\title{
Necropsy as a means to gain additional information about causes of dairy cow deaths
}

\author{
P. T. Thomsen, ${ }^{\star 1}$ K. Dahl-Pedersen, $\dagger$ and H. E. Jensen $†$ \\ *Aarhus University, Department of Animal Science, PO Box 50, DK-8830 Tjele, Denmark \\ †University of Copenhagen, Department of Veterinary Disease Biology, Ridebanevej 3, DK-1870 Frederiksberg C, Denmark
}

\begin{abstract}
High mortality among dairy cows constitutes a problem both financially and in relation to animal welfare. Knowledge about causes of death is a fundamental step toward reducing cow mortality. Several studies have evaluated causes of dairy cow deaths. However, the vast majority of studies describing causes of death are based on questionnaires with farmers or veterinarians. It is uncertain to what degree such information is sufficient and reflects the true cause of death or euthanasia. In this study, proximate causes of death were evaluated based on a thorough necropsy of a random sample of 79 Danish dairy cows at an incineration plant. The necropsy was combined with information about the farmer's perception regarding the cause of death and information about disease treatments from the Danish Cattle Database. Pneumonia and locomotor disorders were found to be the most predominant proximate causes of death. Often the death occurred after a prolonged period during which the cow suffered several different disorders, even though this was often not noticed by the farmer. Causes of death stated by the farmers agreed with the necropsy results in 50 to $64 \%$ of cases. Information about disease treatments from the Danish Cattle Database agreed with the necropsy results in 34 to $39 \%$ of cases. All 3 sources of information about cause of death agreed in only 1 out of 4 cases, and even when the farmer and the disease recordings did agree with the necropsy results, the latter often gave additional information about the cause of death. In many situations, therefore, a necropsy may be a valuable tool when trying to control excessive cow mortality in a herd.
\end{abstract}

Key words: necropsy, cause of death, dairy cow

Received April 16, 2012.

Accepted June 5, 2012.

${ }^{1}$ Corresponding author: petert.thomsen@agrsci.dk

\section{INTRODUCTION}

Dairy cow mortality has increased in both Denmark and the United States during the last decades. In Denmark, annual mortality rates have increased from approximately $2 \%$ in 1990 to $6 \%$ in 2011 (Thomsen et al., 2004; Danish Cattle Federation, 2012). In the United States, cow mortality has increased significantly during recent years to a level of 5 to $6 \%$ in 2005 (USDA, 2007; Miller et al., 2008). Such high levels of cow mortality constitute a major problem, both financially and in relation to animal welfare (Thomsen and Houe, 2006).

Knowledge about cause of death is a fundamental step toward preventing future deaths. Several studies have evaluated causes of dairy cow deaths. However, most studies with a focus on cause of death are based on questionnaires with farmers or veterinarians (e.g., Menzies et al., 1995; Esslemont and Kossaibati, 1997; Thomsen et al., 2004). It is uncertain to what degree cause of death as stated by the farmer (or the local veterinarian) in fact reflects the true underlying pathology leading to death. A necropsy can be defined as a thorough postmortem evaluation of an unassisted dead or euthanized cow with the objective to disclose any patho-anatomical findings. Only a few studies have carried out necropsies to evaluate causes of death in dairy cows. McConnel et al. $(2009,2010)$ evaluated causes of dairy cow deaths in 1 and 3 dairy herds, respectively, and concluded that, in many cases, necropsies could give valuable information about causes of death. Watson et al. (2008) reviewed diagnostic laboratory submissions of unassisted dead dairy cows in England and Wales. Out of 142 submissions from dairy cows, 84 were carcasses. The cows included in their study should be considered a biased sample, as cows are typically submitted to a diagnostic laboratory when no cause of death is evident or when mortality in a herd suddenly increases. The present study is the first to use necropsies to evaluate causes of death in a random sample of cows from many different herds. Our objectives were to evaluate (1) cause of death among a sample of dead and euthanized cows and (2) to what degree a necropsy would reveal information that was not already available 
based on the farmer's perception of cause of death and the cow's disease history.

\section{MATERIALS AND METHODS}

All cows that die on farm in Denmark (euthanized and unassisted dead cows) are processed at one incineration plant (DAKA, Assentoft, Denmark). Danish farmers are not allowed to dispose of dead cows in any other way. Farmers order pick-up of a dead cow via an automatic phone system or a webpage and are charged a fee for disposal of the cow. If the carcass is partly rotten, the farmer is charged an extra fee. Typically, cows arrive at the incineration plant the day after they have died. In most cases, cows are therefore relatively fresh when arriving at DAKA.

Necropsies took place at DAKA from January to May 2011. The majority of Danish dairy cows (93\%) are from herds in the Jutland and Funen regions, and DAKA is placed centrally in Jutland (which houses $87 \%$ of all Danish dairy cows). Cows from the rest of Denmark (Zealand and other islands) typically arrive at DAKA 1 d later after death compared with cows from Jutland and Funen. Therefore, we decided to include only cows from Jutland and Funen to evaluate carcasses as soon after death as possible. At DAKA, cows to be included in the study were selected randomly among cows from conventional (i.e., not organic) herds with at least 50 cows and Danish Holstein as the predominant breed. Additionally, only cows from herds with an annual herd-level mortality rate for 2010 among the worst $25 \%$ of Danish dairy herds $(>7.6 \%)$ were sampled. Out of 3,990 Danish dairy herds, 3,031 were conventional and had $\geq 50$ cows. Among these, 830 had an annual mortality rate $>7.6 \%$, and 788 of these were located in Jutland or Funen. Cows to be necropsied were sampled using systematic random sampling based on a list of these 788 herds.

Cows were subjected to a total necropsy based on the procedure described by Jensen (2011). The necropsy was performed by a veterinarian with specialist training in pathology. Necropsy of each individual cow took approximately $1 \mathrm{~h}$ and included external and internal inspection, palpation, and relevant incisions. All internal organs were thoroughly examined. All joints of all 4 legs were opened and inspected. All hooves, digital bones, and heads were sagittally sectioned for inspection using a bandsaw. Other bones were sectioned on indication. All lesions were recorded and documented by digital photos. Based on the amount of reparative changes (typically by the formation of granulation tissue and fibrosis), the durations of lesions were scored as short
( $<2 \mathrm{wk}$ ) or long ( $\geq 2 \mathrm{wk}$ ). Additionally, a specimen of ileum from all cows was sampled for histopathological examination for changes indicative of paratuberculosis, as described by Huda and Jensen (2003).

A proximate cause of death was established based on the necropsy findings. In many cases, the death of a dairy cow is caused by a continuum of events. However, the proximate cause of death has been defined as the most likely immediate cause of the death (McConnel et al., 2009). Proximate causes of death were grouped into 8 major groups as originally suggested by Thomsen and Houe (2006) based on an extensive review of the literature and later used by McConnel et al. (2009): accidents, calving disorders, digestive disorders, locomotor disorders, metabolic disorders, udder/teat disorders, other known reasons, and unknown reasons. Secondary findings were defined as pathological changes that did not directly cause the death of the cow but that may have contributed to the final outcome; that is, death or euthanasia.

Immediately after the necropsy at DAKA, the dairy farmer was contacted by mail. The letter explained the background and purpose of the study, guaranteed confidentiality, and informed the farmer that we would contact him or her within the next few days to ask a few questions about the death. During the subsequent phone interview, the farmer was asked whether the cow died unassisted or was euthanized and the farmer was asked his or her opinion regarding the cause of death using an open question. Additionally, the farmer was asked to estimate the duration of the disease leading to death. Duration was scored as short $(<2$ wk) or long $(\geq 2$ wk). Finally, the farmer was asked about housing system, milking system, and the use of grazing.

When a cow is medically treated in Denmark, the farmer or veterinarian (depending on who provides the treatment) must report the treatment to the Danish Cattle Database. Information about disease treatments for all cows included in the study was retrieved from the database for the entire life of the cow. Disease treatments for each individual cow were scrutinized manually and all treatments (excluding routine vaccinations and pregnancy tests) within a period of 3 mo before the death of the cow were regarded as relevant in relation to the death. In a few cases, disease treatments occurring more than 3 mo before the death were also considered if it was obvious that the treatments constituted a continuum. Information about parity, date of birth, calving(s), and death for all cows, and data on milk yield, herd size, and mean annual herd-level mortality rate for all herds were obtained from the Danish Cattle Database. 


\section{RESULTS}

In total, 92 cows were examined at DAKA. The cows examined constituted 5 to $10 \%$ of the cows processed at DAKA on each day of the study. In 5 cases (3 different farmers), the farmer did not wish to participate in the study and in 8 cases (4 different farmers), the farmer did not remember the specific cow. These cows were excluded from the analysis and the final data set thus included complete information about 79 cows from 69 herds. Of these cows, 47 were euthanized and 32 died unassisted.

Mean annual herd-level mortality rate among the 69 herds included in the study was 10.0\% [median 9.2, quartile (Q)1: 7.6; Q3: 11.8]. Annual mortality rate in the 3 herds declining to participate was 17.7, 11.0, and $24.7 \%$, respectively. Mean herd size was 227 cows (median: 181; minimum: 51; Q1: 129; Q3: 268; maximum: 616). In comparison, herd sizes of herds where the farmer did not remember the specific cow when interviewed were $841,433,135$, and 1,038 cows, respectively. Mean annual milk yield among the study herds was $8,147 \mathrm{~kg}$ of milk with a range of 6,205 to 10,081 $\mathrm{kg}$. Sixty-one herds had loose housing systems with cubicles, 1 herd had deep litter loose housing, and 7 herds had tie stalls. Of the 62 herds with loose housing systems, 15 had automatic milking systems (milking robots) and 47 had traditional milking systems. In 50 of the herds, cows were not grazing outside during summer, in 14 herds both lactating and dry cows grazed, and in 5 herds only dry cows were grazing. Among cows included in the study, $35.2 \%$ died during first lactation, $32.4 \%$ during second lactation, and $32.4 \%$ during third or later lactations. Cows died at a mean age of 1,414 d (median: 1,292; minimum: 745; Q1: 989; Q3: 1,727; maximum: 2,776). Cows died on average $71 \mathrm{~d}$ after calving. The distribution of days from calving to death is illustrated in Figure 1. Figure 2 illustrates the distribution of deaths within the first $30 \mathrm{~d}$ after calving.

The proximate cause of death for euthanized and unassisted dead cows is presented in Table 1. In 2 cases, necropsy could not determine a cause of death. In a euthanized cow, the only abnormal finding was a defect in the left side of the diaphragm through which parts of the liver had become adherent to the caudal part of the left lung. In an unassisted dead cow, the only abnormal finding was a blood clot measuring approximately 20 $\times 20 \times 20 \mathrm{~cm}$ found in the rumen. The origin of the blood could not be determined. In the rest of the cows (97\%), the necropsy indicated a likely cause of death or euthanasia. Based on the histopathological evaluation, paratuberculosis was not diagnosed in any of the cows.

Agreement between causes of death originating from necropsy, farmer, and disease recordings is illustrated

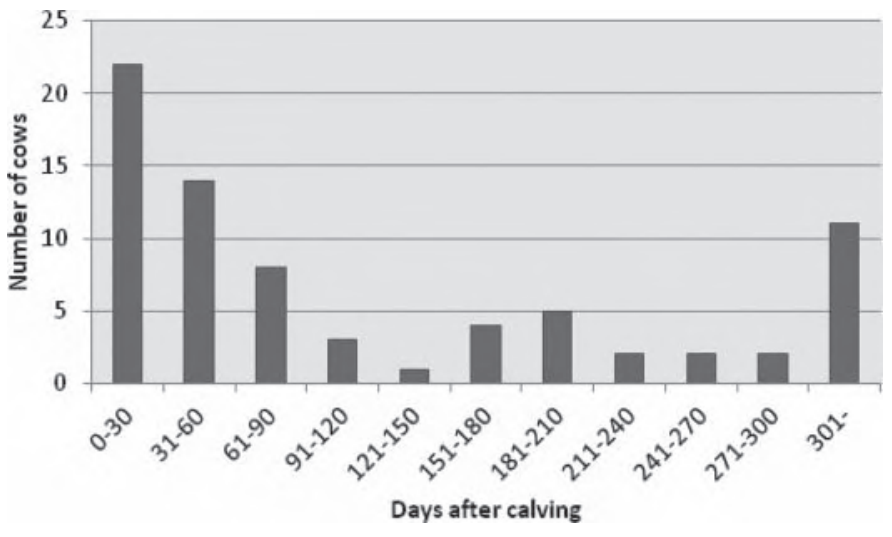

Figure 1. Distribution of deaths (unassisted death and euthanasia) in relation to days after calving in a sample of necropsied Danish dairy cows.

in Table 2. For unassisted dead cows, all 3 sources of information came up with the same cause in $25 \%$ of the cases, whereas no agreement was found in $41 \%$ of all cases. In total, necropsy and farmer agreed about the cause in $50 \%$ of cases. In $28 \%$ of euthanized cows, all 3 sources agreed on the cause of death, whereas in $19 \%$ of cases no agreement was found; in $64 \%$ of cases, necropsy and farmer reported the same cause. In $34 \%$ of the euthanized cows and $47 \%$ of the unassisted dead cows, no disease treatments were recorded in the Danish Cattle Database.

In $61 \%$ of all cases, the farmer estimated that the course of disease(s) leading to death had been short. A short duration was estimated by the farmer in $55 \%$ of euthanized cows and $69 \%$ of unassisted dead cows. In contrast, based on patho-anatomical findings during necropsy, duration was estimated as short in only $23 \%$ of cases (19\% of euthanized cows and $28 \%$ of unassisted dead cows).

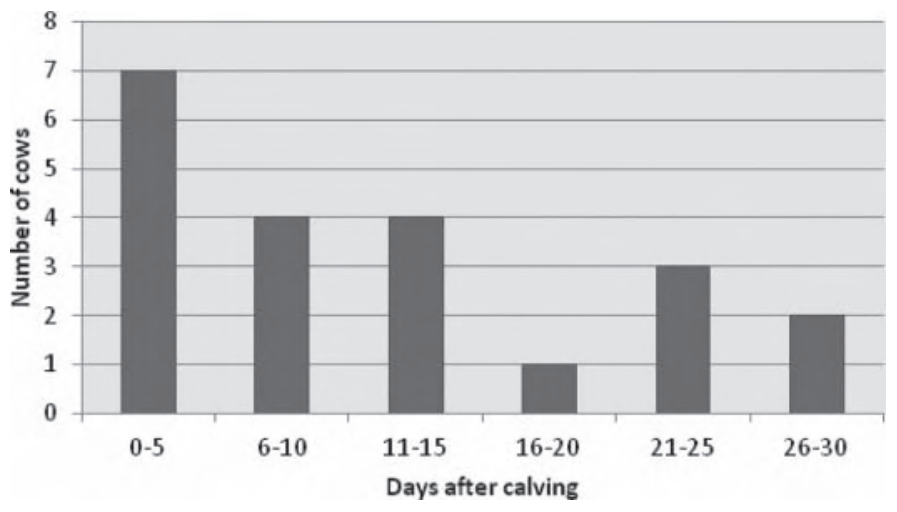

Figure 2. Distribution of deaths (unassisted death and euthanasia) in relation to days after calving in a sample of necropsied Danish dairy cows dying within the first $30 \mathrm{~d}$ after calving. 
Table 1. Proximate causes of death or euthanasia based on necropsy findings in 79 Danish dairy cows

\begin{tabular}{|c|c|c|c|c|}
\hline \multirow[b]{2}{*}{ Cause of death } & \multicolumn{2}{|c|}{ Euthanized cows } & \multicolumn{2}{|c|}{ Unassisted dead cows } \\
\hline & $\begin{array}{l}\text { Cows } \\
\text { (no.) }\end{array}$ & $\begin{array}{c}\text { Euthanasia } \\
(\%)\end{array}$ & $\begin{array}{l}\text { Cows } \\
\text { (no.) }\end{array}$ & $\begin{array}{c}\text { Deaths } \\
(\%)\end{array}$ \\
\hline \multicolumn{5}{|l|}{ Accidents } \\
\hline Luxation of hip joint & 2 & & 0 & \\
\hline Fracture & 1 & & 0 & \\
\hline Strangulation & 0 & 6 & 1 & 3 \\
\hline \multicolumn{5}{|l|}{ Calving disorders } \\
\hline Vaginal laceration/rupture/prolapse & 4 & & 1 & \\
\hline Dystocia & 1 & & 0 & \\
\hline Endometritis & 0 & 11 & 1 & 6 \\
\hline \multicolumn{5}{|l|}{ Digestive disorders } \\
\hline Hemorrhagic enteritis/rumenitis & 0 & & 2 & \\
\hline Volvulus & 0 & & 1 & \\
\hline Left displaced abomasum & 1 & 2 & 2 & 16 \\
\hline \multicolumn{5}{|l|}{ Locomotor disorders } \\
\hline Sole ulcer/laminitis & 2 & & 1 & \\
\hline Arthritis & 11 & & 2 & \\
\hline Osteomyelitis & 2 & & 0 & \\
\hline Arthrosis & 3 & & 0 & \\
\hline Other locomotor disorders & 3 & 45 & 0 & 9 \\
\hline \multicolumn{5}{|l|}{ Metabolic disorders } \\
\hline Fatty liver (ketosis) & 2 & 4 & 1 & 3 \\
\hline \multicolumn{5}{|l|}{ Udder/teat disorders } \\
\hline Necrotic mastitis & 3 & 6 & 3 & 9 \\
\hline \multicolumn{5}{|l|}{ Other known reasons } \\
\hline (Broncho-)pneumonia & 6 & & 7 & \\
\hline Ischemic necrosis/hemorrhage, thigh & 4 & & 3 & \\
\hline Pericarditis & 1 & & 1 & \\
\hline Endocarditis & 0 & & 3 & \\
\hline Peritonitis & 0 & 23 & 2 & 50 \\
\hline Unknown reason & 1 & 2 & 1 & 3 \\
\hline
\end{tabular}

\section{DISCUSSION}

All 3 sources of information about the cause of death agreed in approximately one-fourth of all cases. Farmers agreed with the necropsy findings in one-half to two-thirds of all cases. The lowest agreement was found between information about disease treatments from the Danish Cattle Database and necropsy findings or the farmers' opinion. In $39 \%$ of all cases, no disease treatments were recorded. Bartlett et al. (2001) demonstrated an underreporting of cases of clinical mastitis to the Danish Cattle Database. To include only cows from herds with high herd-level cow mortality in the present study was decided in collaboration with the Danish Cattle Federation to support a campaign with special focus on reducing cow mortality in problem herds. Farmers with high cow mortality might have less accurate disease recognition and recording compared with an average herd, which could have affected these results. McConnel et al. (2009) compared farmer perception and necropsy results in a single dairy herd and found that the farmer was correct in $55 \%$ of cases

Table 2. Agreement between proximate causes of death based on necropsy findings, farmer's perception, and recordings of disease treatments from the Danish Cattle Database in a sample of 79 dead or euthanized dairy cows

\begin{tabular}{|c|c|c|}
\hline \multirow[b]{2}{*}{ Agreement } & \multicolumn{2}{|c|}{ Percentage of cases } \\
\hline & $\begin{array}{c}\text { Unassisted dead } \\
\text { cows }\end{array}$ & $\begin{array}{l}\text { Euthanized } \\
\text { cows }\end{array}$ \\
\hline All 3 sources & $25(\mathrm{n}=8)$ & $28(\mathrm{n}=13)$ \\
\hline Necropsy and farmer & $25(\mathrm{n}=8)$ & $36(\mathrm{n}=17)$ \\
\hline Necropsy and disease recordings & $9(\mathrm{n}=3)$ & $11(\mathrm{n}=5)$ \\
\hline Farmer and disease recordings & $0(\mathrm{n}=0)$ & $6(\mathrm{n}=3)$ \\
\hline None & $41(\mathrm{n}=13)$ & $19(\mathrm{n}=9)$ \\
\hline
\end{tabular}


but stated that if the most obvious cases (locomotor disorders and accidents) were excluded, the farmer was correct in only $41 \%$ of the cases.

Even when farmers and disease recordings did agree with the necropsy findings, the level of detail often differed significantly. As an example, a euthanized cow was reported as being "unable to use a leg" by the farmer. Disease recordings showed that the cow was treated for interdigital phlegmon on 3 consecutive days 4 wk before euthanasia and for swollen hock on 3 consecutive days 2 wk before euthanasia. Necropsy findings showed that the cow had "a chronic ulceration medial to the right hock joint with an underlying abscess (approximately $5 \mathrm{~cm}$ in diameter with fistulation to the skin surface), osteomyelitis in the distal part of the metatarsal bone with periarticular fibrosis around the metatarsal joint and a moderate fatty liver." Even though all 3 sources of information agreed that the cow was euthanized due to a locomotor disorder, it is evident that the necropsy findings were much more precise and informative regarding the nature of lesions leading to euthanasia.

A proximate cause of death could be established in the majority of cases. Nevertheless, it was obvious that cows often died or were euthanized because of several underlying pathological processes. A continuum of minor diseases from which the cow did not recover was, in many cases, what eventually caused death. Farmers generally estimated the duration as short compared with estimates based on the necropsy findings. This may indicate that farmers often notice only the final stages of a longer disease progression that finally leads to death. Farmers with high cow mortality in their herd might perform worse than average in relation to early identification of sick cows. Many cows had more than one chronic lesion and it is likely that the combination of more than one disease or lesion would increase the risk of the cow dying. Cows with generally compromised production and health have been termed "loser cows" and it has been shown that loser cows have a significantly increased risk of dying (Thomsen et al., 2007).

Locomotor disorders were the single largest group of proximate causes of death, constituting $45 \%$ of all cases of euthanasia and $9 \%$ of all unassisted dead cows. Additionally, locomotor disorders played a major role as secondary findings. Arthritis was found in $61 \%$ of the cows, and $84 \%$ of all cows had one or more locomotor disorders diagnosed during the necropsy. These findings are in agreement with Thomsen et al. (2004), who, in a study based on a questionnaire survey of 196 Danish dairy farmers, found locomotor disorders to be the single most important reason for euthanasia. In that study, $40 \%$ of all cases of euthanasia were due to lo- comotor disorders. McConnel et al. (2009) also found severe limb injury to be the most prevalent cause of death in a sample of 94 dead cows from one herd.

Pneumonia was found to be the proximate cause of death in 7 dead and 6 euthanized cows. In many cases, the pneumonia was associated with "hardware disease," because evidence of a foreign object penetrating the thoracic cavity from the rumen was found. In cases where the proximate cause of death was pneumonia but the ultimate cause was hardware disease, the perception of the farmer (and disease recording) was recorded as correct irrespective of whether the farmer stated pneumonia or hardware disease as the cause of death. Two cases of pericarditis were also associated with hardware disease. In agreement with our results, McConnel et al. (2009) found a relatively high proportion of cows (approximately 11\% of 94 cows from a single herd) to have pneumonia as cause of death. The proportion of euthanized cows and the distribution of deaths in relation to lactation stage were in agreement with results from previous studies (Thomsen et al., 2004; Thomsen and Sørensen, 2008).

Performing a necropsy incurs extra costs on the farmer and may be seen as impractical and timeconsuming (McConnel et al., 2010). Watson et al. (2008) concluded that carcasses had more diagnostic value than other types of samples submitted to diagnostic laboratories. In the present study, necropsies often provided additional information compared with what was already known based on the perception of the farmer and available disease recordings. Even in cases where the proximate cause of death was known, the necropsy often added valuable detail about the sequence of events leading to the death of the cow. Our results have shown that disease recognition is often suboptimal (illustrated by the fact that many cows die without any treatment records and sometimes without the farmer knowing what went wrong) and needs to be improved in many herds. A necropsy can help dairy farmers identify where they failed to accurately identify and manage sick cows and thus help prevent future deaths. A necropsy may not be worth the extra cost and time when cows die for obvious reasons (e.g., a cow euthanized due to vaginal rupture associated with dystocia) in herds with no major problems with dairy cow mortality. However, in accordance with McConnel et al. (2010), we recommend that necropsies be performed when no obvious cause of death can be identified, when herd-level mortality is high or increasing, or to confirm tentative diagnoses. In such cases, a necropsy may be a good investment for the farmer, especially if it is combined with other sources of information, such as antemortem clinical examinations, production records, 
and recordings of disease treatments (McConnel et al., 2010). A necropsy under field conditions may not necessarily involve all the procedures performed in this study (e.g., sectioning of hooves) but could be based on indications and adapted in each case (e.g., based on the disease history of the cow). This approach could, in many cases, make the necropsy simpler and easier to perform and thus cheaper.

\section{CONCLUSIONS}

Necropsies performed as part of this study have shown that Danish dairy cows die due to a variety of wellknown production diseases. Pneumonia (often associated with hardware disease) and locomotor disorders in particular were major proximate causes of death. Death often occurred after a prolonged period during which a cow had several different disorders, even though this may not have been noticed by the farmer. Causes of death stated by the farmers agreed with necropsy results in 50 to $64 \%$ of cases. Information about disease treatments from the Danish Cattle Database agreed with the necropsy results in 34 to $39 \%$ of cases. Onethird to one-half of all dead cows had no disease treatments recorded. All 3 sources of information regarding cause of death agreed in only 1 out of 4 cases, and even when the farmer and the disease recordings agreed with the necropsy results, the latter often yielded additional information about the cause of death.

\section{ACKNOWLEDGMENTS}

The authors thank Dennis Brok and Frederik Andersen (both of Department of Veterinary Disease Biology, University of Copenhagen, Frederiksberg C, Denmark) for valuable practical help with the necropsies.

\section{REFERENCES}

Bartlett, P. C., J. F. Agger, H. Houe, and L. G. Lawson. 2001. Incidence of clinical mastitis in Danish dairy cattle and screening for non-reporting in a passively collected national surveillance system. Prev. Vet. Med. 48:73-83.

Danish Cattle Federation. 2012. Cow mortality: Figures on cattle from the Danish Cattle Federation. Accessed mon/day/year. Accessed Apr. 12, 2012. http://www.landbrugsinfo.dk/kvaeg/tal-om-kvaeg/ sider/kododmain.aspx.

Esslemont, R. J., and M. A. Kossaibati. 1997. Culling in 50 dairy herds in England. Vet. Rec. 140:36-39.

Huda, A., and H. E. Jensen. 2003. Comparison of histopathology, cultivation of tissues and rectal contents, and interferon-gamma and serum antibody responses for the diagnosis of bovine paratuberculosis. J. Comp. Pathol. 129:259-267.

Jensen, H. E. 2011. Necropsy of ruminants. Pages 33-59 in NecropsyA Handbook and Atlas. H. E. Jensen, ed. Biofolia, Copenhagen, Denmark.

McConnel, C. S., F. B. Garry, J. E. Lombard, J. A. Kidd, A. E. Hill, and D. H. Gould. 2009. A necropsy-based descriptive study of dairy cow deaths on a Colorado dairy. J. Dairy Sci. 92:1954-1962.

McConnel, C. S., F. B. Gerry, A. E. Hill, J. E. Lombard, and D. H. Gould. 2010. Conceptual modeling of postmortem evaluation findings to describe dairy cow deaths. J. Dairy Sci. 93:373-386.

Menzies, F. D., D. G. Bryson, T. McCallion, and D. I. Matthews. 1995. A study of mortality among suckler and dairy cows in Northern Ireland in 1992. Vet. Rec. 137:531-536.

Miller, R. H., M. T. Kuhn, H. D. Norman, and J. R. Wright. 2008 Death losses for lactating dairy cows in herds enrolled in dairy herd improvement test plans. J. Dairy Sci. 91:3710-3715.

Thomsen, P. T., and H. Houe. 2006. Dairy cow mortality-A review. Vet. Q. 28:122-129.

Thomsen, P. T., A. M. Kjeldsen, J. T. Sørensen, and H. Houe. 2004. Mortality (including euthanasia) among Danish dairy cows (19902001). Prev. Vet. Med. 62:19-33.

Thomsen, P. T., S. Østergaard, J. T. Sørensen, and H. Houe. 2007. Loser cows in Danish dairy herds: Definition, prevalence and consequences. Prev. Vet. Med. 79:116-135.

Thomsen, P. T., and J. T. Sørensen. 2008. Euthanasia of Danish dairy cows evaluated in two questionnaire surveys. Acta Vet. Scand. 50:33.

USDA (US Department of Agriculture). 2007. Dairy 2007, Part II: Changes in the U.S. dairy cattle industry 1991-1007. USDAAPHIS-VS, CEAH, Fort Collins, CO.

Watson, E. N., G. P. David, and A. J. C. Cook. 2008. Review of diagnostic laboratory submissions of adult cattle 'found dead' in England and Wales in 2004. Vet. Rec. 163:531-535. 